\title{
Simulation of the Primary Frequency Control Pre-Qualification Test for a 5MW Wind Turbine
}

\author{
Narender Singh, Jeroen D. M. De Kooning, Lieven Vandevelde \\ Department of Electrical Energy, Metals, Mechanical Constructions \& Systems (EEMMeCS) \\ Faculty of Engineering \& Architecture, Ghent University, Belgium
}

\begin{abstract}
The global wind power capacity is on a constant rise. Many countries are moving towards renewable energy sources. Wind energy accounts for the biggest renewable energy resource in Europe. Despite all the benefits, wind energy tends to weaken the grid stability. One reason for this is the fact that most wind turbine generators are not directly coupled to the grid and do not provide ancillary services, such as primary frequency control, due to the lack of rotating inertia. This paper presents detailed models of a wind turbine with a permanent magnet synchronous generator (PMSG). This model is used to test the feasibility of providing ancillary services by performing the pre-qualification test for primary frequency control, as established by the Belgian Transmission System Operator (TSO). These tests are conducted under 4 different wind profiles, each having a different level of turbulence.
\end{abstract}

Index Terms-Ancillary services, Offshore energy, Permanent magnet synchronous generator, Primary frequency control, Wind energy

\section{INTRODUCTION}

The global installed wind power capacity in 2018 was $591 \mathrm{GW}$, of which $51.3 \mathrm{GW}$ was installed in 2018 itself. Currently, wind energy attracts the highest investment among all renewable energy resources. Of the $€ 42.2$ billion that was invested in Europe in renewable energy, $€ 26.7$ billion was spent on wind energy. Currently, in many countries, a high share of the annual power demand is met by wind energy, e.g., $41 \%$ in Denmark, 28\% in Ireland and 24\% in Portugal [1].

Traditional power systems consisted of large synchronous machines having a high rotating inertia that could be utilized to stabilise the grid in case of grid frequency deviations. However, modern power systems with a high penetration of wind energy tend to have a lower synchronous inertia. One such incidence that happened due to low synchronous inertia caused a blackout in South Australia affecting 1.7 million people, along with an economic loss of A\$367 million [2]. In light of such events, strict grid codes are now being implemented that require wind farms to provide ancillary services. Hydro-Québec, a power utility in Canada, has set up grid codes that require any wind farm with a rated power greater than $10 \mathrm{MW}$ to be equipped with a frequency control system [3].

This work is supported by the BEOWIND project, funded by the Energy Transition Fund of the Belgian federal government and the FWO research project G.0D93.16N, funded by the Research Foundation Flanders.
This paper presents a model consisting of an offshore wind turbine coupled with a Permanent Magnet Synchronous Generator (PMSG). The system is controlled in a manner that the output power of the PMSG follows the reference power provided to it. This reference power can be dependent on the grid frequency. However, for the tests presented in this paper, the reference power is based on a pre-qualification test set up by the Belgian TSO Elia for the power plants to be eligible as a Frequency Containment Reserve (FCR) provider. This test requires the production unit to respond to the changing reference value within a short time span. The controller is designed to respond to these changes. The model is additionally stress-tested by subjecting it to different intensity of wind levels. These wind profiles range from steady wind to highly turbulent winds.

\section{MODEL}

There are two essential models, viz. a wind turbine model developed in FAST, which is an aero-elastic computer-aided engineering (CAE) tool for horizontal axis wind turbines, and a PMSG model developed in MATLAB Simulink. The two models interact with each other using an S-function in the Simulink environment.

\section{A. Wind turbine}

The wind turbine model used for this paper is a $5 \mathrm{MW}$ offshore reference wind turbine [4]. This model is implemented in FAST by the National Renewable Energy Laboratory (NREL). FAST is a tool for simulating the coupled dynamic response of wind turbines. This elaborate software combines aerodynamic, hydrodynamic, structural and electrical system models of different types of wind turbines. However, for the analysis presented in this paper, the electrical model is developed separately in MATLAB Simulink. The main properties of the simulated wind turbine are listed in Table I.

Fig. 1 shows the power coefficient $C_{p}$ vs tip-speed ratio (TSR) curve of the turbine. This curve is obtained by simulating the turbine under different wind conditions ranging from $3 \mathrm{~m} / \mathrm{s}$ to $25 \mathrm{~m} / \mathrm{s}$. The $\mathrm{C}_{\mathrm{p}}$ and TSR values are averaged for each step in the steady state. The operation of the wind turbine follows this curve depending on the wind conditions and the reference power. 
In Fig. 2, the $C_{p}$ curve for one of the simulated cases is presented. The value of $C_{p}$ during this test ranges between 0.49 and 0.26 based on the reference power variation for the duration of the test.

Table I Main properties of the simulated wind turbine

\begin{tabular}{|l|l|}
\hline \multicolumn{1}{|c|}{ Property } & \multicolumn{1}{c|}{ Specification } \\
\hline Power rating & $5 \mathrm{MW}$ \\
\hline Rotor Orientation, Configuration & Upwind, 3 blades \\
\hline Rotor diameter, Hub diameter & $126 \mathrm{~m}, 3 \mathrm{~m}$ \\
\hline Hub height & $90 \mathrm{~m}$ \\
\hline Cut-in, Rated \& Cut-out wind speeds & $3 \mathrm{~m} / \mathrm{s}, 11.4 \mathrm{~m} / \mathrm{s.} 25 \mathrm{~m} / \mathrm{s}$ \\
\hline Cut-in \& Rated rotor speeds & $6.9 \mathrm{rpm}, 12.1 \mathrm{rpm}$ \\
\hline Rated tip speed & $80 \mathrm{~m} / \mathrm{s}$ \\
\hline Overhang, Shaft tilt, Precone & $5 \mathrm{~m}, 5^{0}, 2.5^{\circ}$ \\
\hline Rotor mass & $110,000 \mathrm{~kg}$ \\
\hline Nacelle mass & $240,000 \mathrm{~kg}$ \\
\hline Tower mass & 347,460 \\
\hline
\end{tabular}

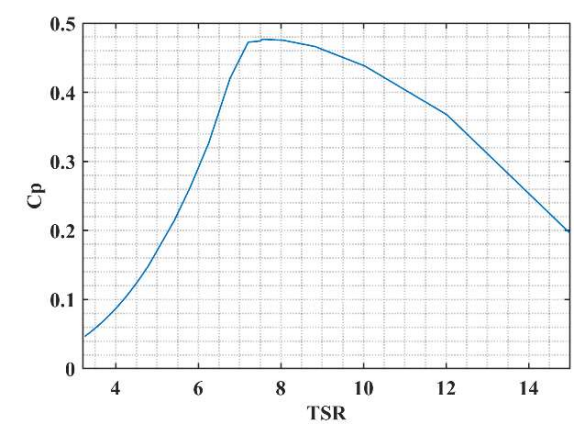

Figure 1: Cp-TSR curve

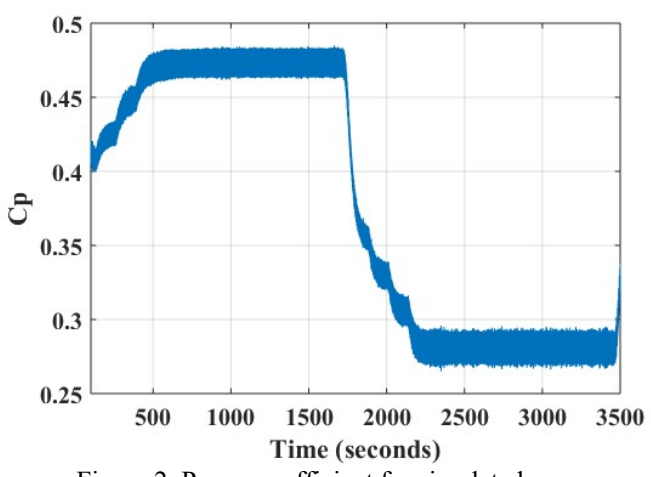

Figure 2: Power coefficient for simulated case

\section{B. Generator}

Classical doubly fed induction generators (DFIG) have been dominant in wind energy. However, in recent times, directdrive PMSG have gained more acceptability as a result of their efficient gearless functioning and high efficiency, especially at high power ratings.

In its typical form, a PMSG has a stator with a three-phase winding and a rotor with permanent magnets. In gearless 'direct-drive' systems the rotor consist of a high number of poles and is directly driven by the wind turbine. The stator winding observes a varying magnetic field which induces a back-emf. With this voltage, power can be delivered by the stator winding to the power-electronic converter.

Fig. 3 gives a schematic representation of a PMSG. The stator is represented by the windings $\mathrm{a}, \mathrm{b}$ and $\mathrm{c}$ whereas the rotor is shown as a magnet with rotating $\mathrm{d}$ and $\mathrm{q}$ axis.

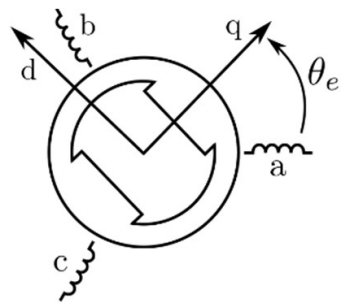

Figure 3: Reference axis in PMSG

The generator is modeled in the rotating $d q$ reference frame. Fig. 4 shows the equivalent scheme for the PMSG used in this paper. Here, $\mathrm{e}_{\mathrm{PM}, \mathrm{q}}$ and $\mathrm{e}_{\mathrm{PM}, \mathrm{d}}$ represent the back-emf voltages induced by the permanent magnets. The $d$ and q equivalents also consist of an additional back-emf each proportional to the current in the other scheme due to the armature reaction effect. In a machine with a purely sinusoidal back-emf waveform and no zero sequence component, only e $\mathrm{ePM}_{\mathrm{P}, \mathrm{q}}$ differs from zero and is a constant, proportional to the rotor speed. $R_{s}$ and $R_{c}$ respectively represent the copper losses in the stator winding and the iron losses. The generator parameters are listed in Table II.
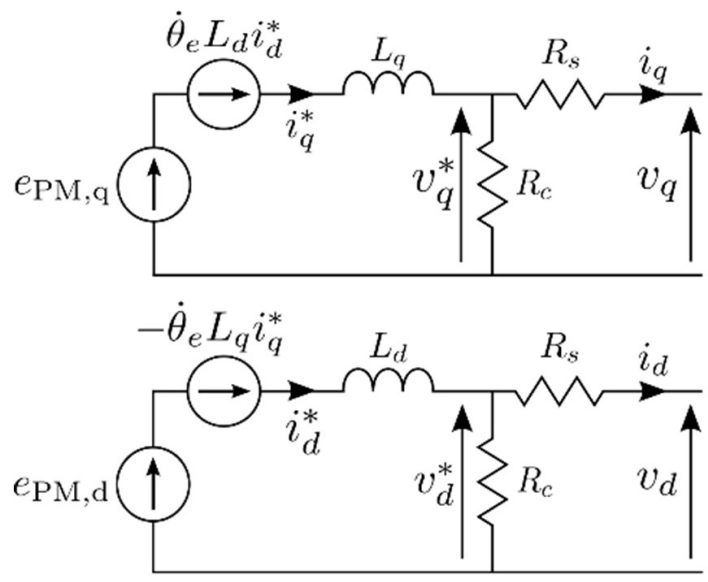

Figure 4: Equivalent scheme of a PMSG in the rotating reference frame

Table II PMSG parameters

\begin{tabular}{|l|l|}
\hline \multicolumn{1}{|c|}{ Property } & \multicolumn{1}{c|}{ Specification } \\
\hline Rated power & $5 \mathrm{MW}$ \\
\hline Rated speed & $12.1 \mathrm{rpm}$ \\
\hline Nominal efficiency & $\approx 93 \%$ \\
\hline Pole pairs & 117 \\
\hline Stator resistance & $0.098504 \mathrm{ohm} / \mathrm{phase}$ \\
\hline Synchronous inductance & $0.009766 \mathrm{p.u}$. \\
\hline
\end{tabular}




\section{CONTROL}

There are various methods for the control of direct-driven PMSG wind turbines [5]-[7]. The control strategy used in this paper is field oriented control, i.e., the direct current component is regulated to zero and the quadrature current is proportional to torque. Fig. 5 shows the field oriented control schematically. This control scheme is used to conduct the tests presented in the next section.

The control system is a PI controller that generates a current signal based on a comparison between the reference power value and the actual power output from the generator at each time step. The reference power that serves as an input to the controller is a time varying signal generated in accordance with the qualifying test presented in the next section. The PI controller is optimized in a manner such that the error is minimized. The controller is tested under different wind conditions, ranging from highly turbulent wind conditions to steady wind. The performance of the controller varies depending on the wind conditions.

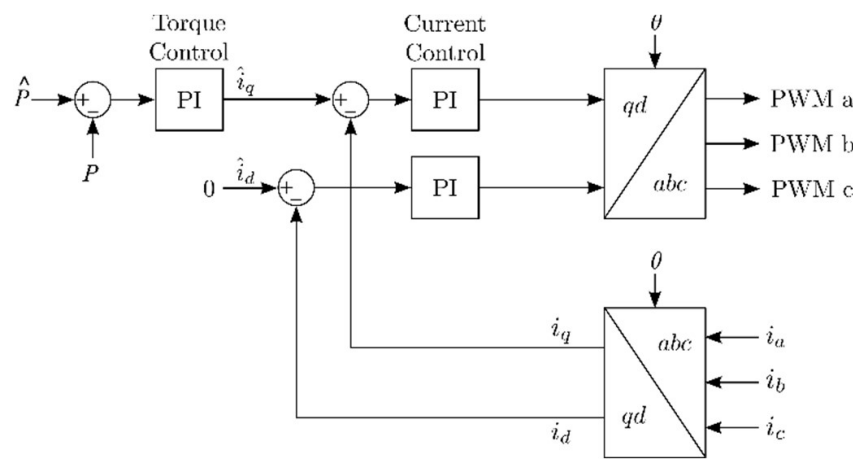

Figure 5: Field oriented control of the PMSG

\section{TESTS}

The Belgian TSO Elia categorizes its grid frequency balancing services as:

- $\quad$ Frequency Containment Reserve (FCR)

- Automatic Frequency Restoration Reserve (AFRR)

- Manual Frequency Restoration Reserve (MFRR)

These names correspond to the classical terminology used for grid balancing services, i.e., Primary, Secondary and Tertiary reserve. The scope of this paper lies within FCR, which is the primary frequency reserve. This service is contracted through two different frameworks setup by Elia, based on the generation capacity of the production units. These contracts are the Contract for the Injection of Production Units (CIPU) and non-CIPU. For a production unit to be eligible to provide FCR services, among other necessary conditions, it must qualify a pre-qualification test set up by Elia. On successful completion of this test, the production unit is eligible as an FCR provider for a duration of 5 years.

Elia provides details of its synthetic frequency profile test in the public domain [8]. The test has been adapted in a manner that it is suitable to be applied on the developed models. The focus of this test is on the $200 \mathrm{mHz}$ type service which implies frequency support within the range of $49.8-50.2 \mathrm{~Hz}$ of grid frequency.

The time series of the pre-qualification test, as provided by Elia, is enlisted in Table III and is followed to simulate this test in the developed model. In order for a wind turbine to be able to provide FCR it must run at a lower power output than its optimal operating point, i.e., the turbine must be curtailed. This is necessary since it allows the wind turbine to regulate the output power both downwards and upwards in order to provide a symmetric $200 \mathrm{mHz}$ control.

Since the used wind turbine model has a nominal power of $5 \mathrm{MW}$, the wind turbine is operated at $4 \mathrm{MW}$ and ramps up and down within the range of 3-5 MW. This implies a non-CIPU contract of $1 \mathrm{MW}$ for the symmetric $200 \mathrm{mHz}$ type service. For all 4 wind types, the average wind speed is above the rated value. In this manner, the rated power can be achieved at all times. However, the power set point is set at $4 \mathrm{MW}$ in order to provide a $1 \mathrm{MW}$ primary reserve band. The function to generate is defined as in (1), here $P_{r e f}$ is the reference power and $P_{P Q T}(t)$ is the power signal of the pre-qualification test, which is time dependent, with values ranging from $-1 \mathrm{MW}$ to $+1 \mathrm{MW}$ based on the simulated test.

$$
P_{\text {ref }}=4 M W+P_{P Q T}(t)
$$

Table III Time series test for service type $200 \mathrm{mHz}$

\begin{tabular}{|c|c|c|c|c|c|c|c|}
\hline Step & $\Delta \mathrm{sec}$ & $\begin{array}{c}\text { From } \\
t=\end{array}$ & $\begin{array}{c}\text { Tot } \\
=\end{array}$ & Step & $\Delta \mathrm{sec}$ & $\begin{array}{c}\text { From } \\
t=\end{array}$ & $\begin{array}{c}\text { Tot } \\
=\end{array}$ \\
\hline \multicolumn{4}{|c|}{ Upward direction } & \multicolumn{4}{|c|}{ Downward direction } \\
\hline Ramp-up & 8 & 0 & 8 & $\begin{array}{l}\text { Ramp } \\
\text { down }\end{array}$ & 8 & 0 & 8 \\
\hline Step up 1 & 120 & 8 & 128 & $\begin{array}{l}\text { Step } \\
\text { down } 1\end{array}$ & 120 & 8 & 128 \\
\hline Ramp up & 8 & 128 & 136 & $\begin{array}{l}\text { Ramp } \\
\text { down }\end{array}$ & 8 & 128 & 136 \\
\hline Step up 2 & 120 & 136 & 256 & $\begin{array}{l}\text { Step } \\
\text { down } 2\end{array}$ & 120 & 136 & 256 \\
\hline Ramp up & 8 & 256 & 264 & $\begin{array}{l}\text { Ramp } \\
\text { down }\end{array}$ & 8 & 256 & 264 \\
\hline Step up 3 & 120 & 264 & 384 & $\begin{array}{l}\text { Step } \\
\text { down } 3\end{array}$ & 120 & 264 & 384 \\
\hline Ramp up & 8 & 384 & 392 & $\begin{array}{l}\text { Ramp } \\
\text { down }\end{array}$ & 8 & 384 & 392 \\
\hline $\begin{array}{l}\text { Full } \\
\text { power up }\end{array}$ & 1320 & 392 & 1712 & $\begin{array}{l}\text { Full } \\
\text { power } \\
\text { down }\end{array}$ & 1320 & 392 & 1712 \\
\hline $\begin{array}{l}\text { Ramp } \\
\text { down }\end{array}$ & 30 & 1712 & 1742 & $\begin{array}{l}\text { Ramp } \\
\text { up }\end{array}$ & 30 & 1712 & 1742 \\
\hline
\end{tabular}

This test was conducted for 4 different levels of wind:

- Wind type A (high turbulence)

- Wind type B (medium turbulence)

- Wind type C (low turbulence)

- $\quad$ Steady wind 
The entire test has a duration of 3500 seconds. Fig. 6 shows a sample section of wind speed data between 500-550 seconds. The turbulence intensity of the different wind types can be observed from the figure. These wind profiles are generated using TurbSim, a tool developed by NREL.

Fig. 7 shows the output power from the tests conducted for different wind turbulence levels. The section of these results is panned in the interval between $600-800$ seconds. The effect of increasing the wind turbulence level can be seen clearly. For the highest turbulence level (wind type A) a maximum variation in output power is observed, whereas, for steady wind, a more stable output power is achieved.

Fig. 8 shows the probability density function for the controller error values for the different wind types. This figure is used to analyze the performance of the controller. It can be seen here that at high turbulence levels, the absolute mean error and standard deviation are the highest, i.e., $0.2241 \%$ and 0.3024 respectively. In lower turbulent wind tests, these values are expectedly lower.

\section{CONCLUSION}

To study the applicability of the developed control design in an actual power network, the tests simulated are based on a prequalification test set up by the Belgian TSO. The results obtained through the simulations prove the capability of wind turbines to provide primary frequency control with a band of $1 \mathrm{MW}$. The tests were conducted for various wind profiles, ranging from steady wind to a very high turbulence. The control design developed for the tests performed effectively for all the tests.

One crucial factor in the simulations is the control algorithm. This discrete control design needs to be matched with the small time step of the model. Also the control output needs to be highly efficient. In order to test these properties of the controller, the model is subjected to different levels of turbulent winds. Although the error level increases with the increasing turbulence intensity, the controller still performs with low absolute error percentage never exceeding $0.2241 \%$. With this research, a controller design has been developed specifically to analyze the pre-qualification of wind turbines as an FCR provider.

This research lies at the base of further development that will entail full scale offshore wind farm models connected to a full scale power grid based on the Belgian power network.

\section{ACKNOWLEDGMENT}

This work is supported by the BEOWIND project, funded by the Energy Transition Fund of the Belgian federal government and the FWO research project G.0D93.16N, funded by the Research Foundation Flanders.

\section{REFERENCES}

[1] Wind Europe (2019). Wind energy in Europe in 2018 Trends and statistics.

[2] R. Yan, N. -Masood, T. Kumar Saha, F. Bai and H. Gu, "The Anatomy of the 2016 South Australia Blackout: A Catastrophic Event in a High Renewable Network," in IEEE Transactions on Power Systems, vol. 33, no. 5, pp. 5374-5388, Sept. 2018.

[3] Hydro-Québec, "Transmission provider technical requirements for the connection of power plants to the Hydro-Québec transmission system", 2009.

[4] J. Jonkman, S. Butterfield, W. Musial, and G. Scott, "Definition of a 5MW Reference Wind Turbine for Offshore System Development," 2009.

[5] S. Li, T. A. Haskew, R. P. Swatloski and W. Gathings, "Optimal and Direct-Current Vector Control of Direct-Driven PMSG Wind Turbines," in IEEE Transactions on Power Electronics, vol. 27, no. 5, pp. 23252337, May 2012.

[6] X. Zeng, T. Liu, S. Wang, Y. Dong and Z. Chen, "Comprehensive Coordinated Control Strategy of PMSG-Based Wind Turbine for Providing Frequency Regulation Services," in IEEE Access, vol. 7, pp. 63944-63953, 2019.

[7] Z. Zhang, Y. Zhao, W. Qiao and L. Qu, "A Discrete-Time Direct Torque Control for Direct-Drive PMSG-Based Wind Energy Conversion Systems," in IEEE Transactions on Industry Applications, vol. 51, no. 4, pp. 3504-3514, July-Aug. 2015.

[8] Elia, "General Framework for Frequency Containment Reserve Service by Non-CIPU resources.”.

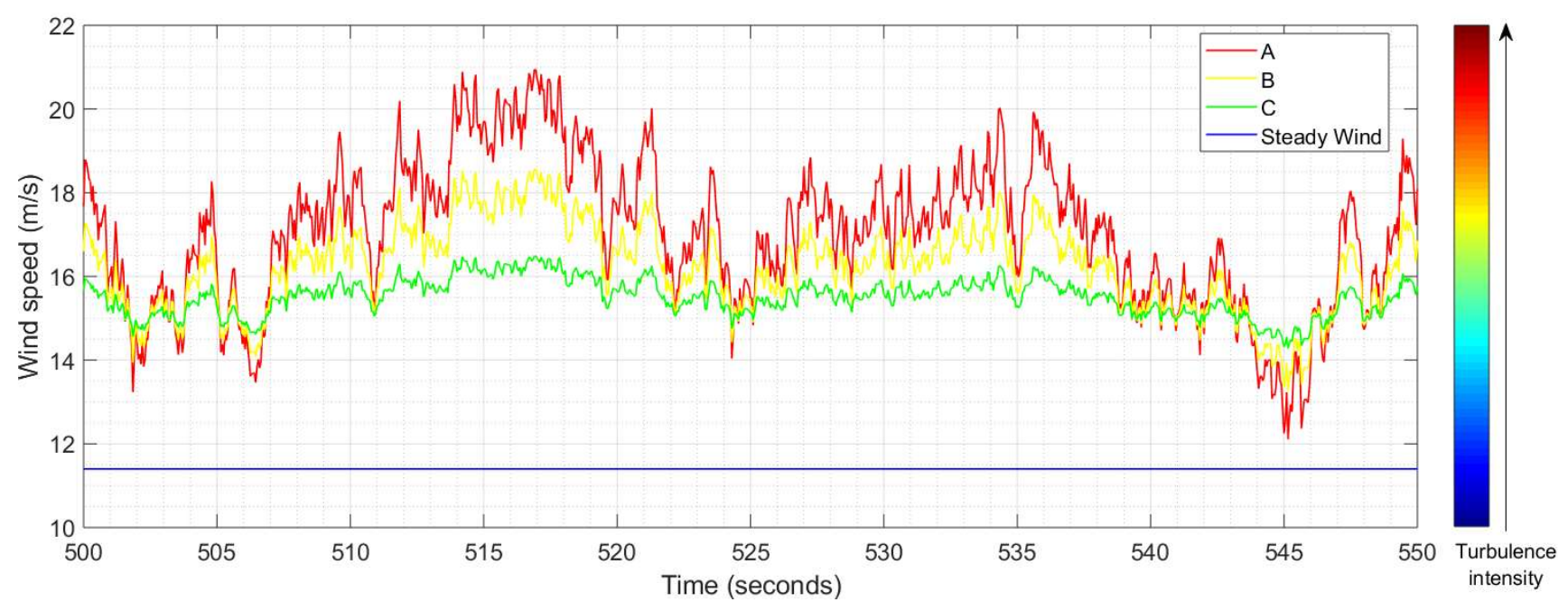

Figure 6: Turbulence intensity level for type A, B, C wind 

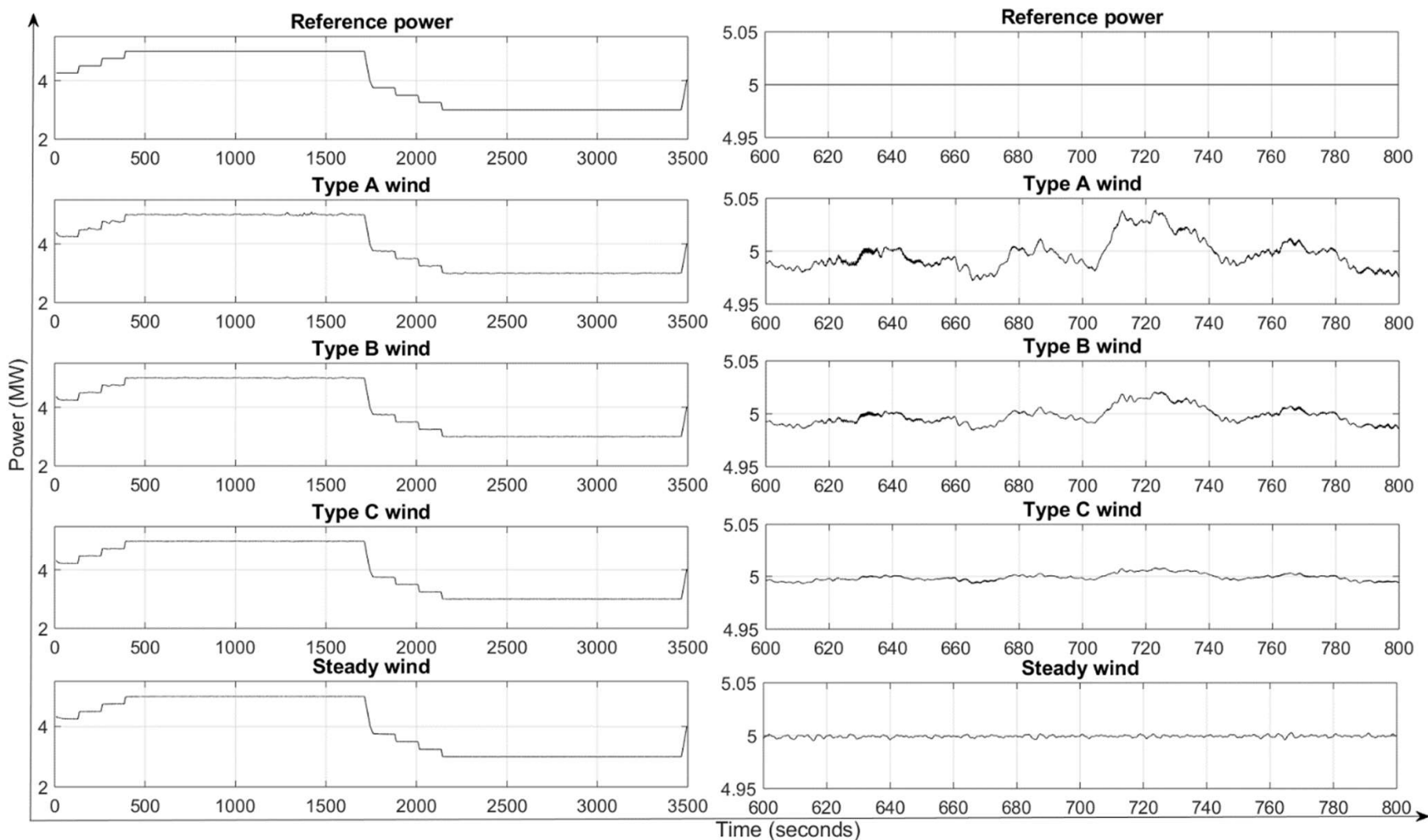

Figure 7: Output power plots for different turbulence test
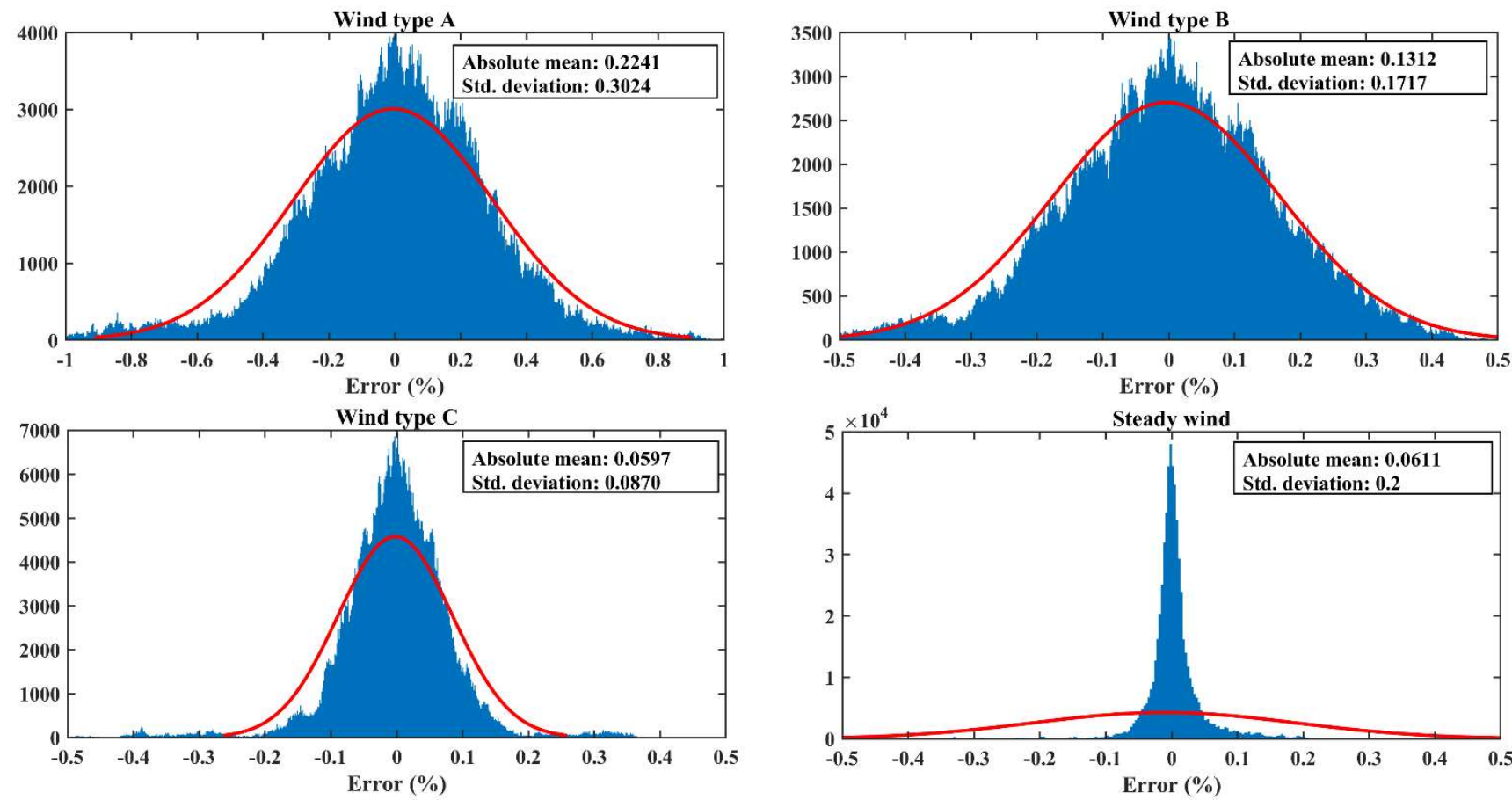

Error - Normal distribution

Figure 8: Probability density function and normal distribution plots for wind type A, B, C and steady wind 